\title{
miR-143 is associated with proliferation and apoptosis involving ERK5 in HeLa cells
}

\author{
FANG ZHENG $^{1}$, JIAHE ZHANG ${ }^{2}$, SIYU LUO $^{2}$, JING YI $^{1}$, PING WANG $^{3}$, QUANQING ZHENG $^{2}$ and YURONG WEN ${ }^{4}$ \\ ${ }^{1}$ Department of Biochemistry and Molecular Biology, School of Basic Medical Science; ${ }^{2}$ Department of Public Health, \\ Public Health Center, Xi'an Jiaotong University; ${ }^{3}$ Department of Obstetrics and Gynecology, \\ Shaanxi Tumor Hospital, Xi'an, Shaanxi 710061; ${ }^{4}$ Center for Translational Medicine, \\ School of Life Science and Technology, Xi'an Jiaotong University, Xi'an, Shaanxi 710049, P.R. China
}

Received May 5, 2015; Accepted July 28, 2016

DOI: $10.3892 / \mathrm{ol} .2016 .5016$

\begin{abstract}
Inappropriate expression of microRNA (miR) is strongly associated with carcinogenesis. miR-143 was reported to be one of the most prominent miRs implicated in the genesis and progression of human cancer. However, its correlation with cell proliferation and apoptosis in cervical cancer remains to be fully elucidated. In the present study, it was demonstrated that miR-143 is able to suppress the proliferation of cervical cancer HeLa cells and induce cell apoptosis in a time- and dose-dependent manner. The present study also investigated the potential targets of miR-143, extracellular-signal-regulated kinase 5 (ERK5) and its downstream substrate oncoprotein c-Fos, both of which are involved in cell proliferation and apoptosis. Upon increasing the miR-143 level, the ERK5 and c-Fos protein expression was significantly decreased without the effect of ERK5 transcription. Therefore, miR-143 is able to suppress cell proliferation and induce apoptosis in HeLa cells, potentially through negative regulation of ERK5 at its post-transcriptional stage.
\end{abstract}

\section{Introduction}

MicroRNAs (miRs) are a group of endogenous RNAs (containing $\sim 23$ nucleotides) that have significant gene expression regulatory roles by pairing to the mRNAs of protein-coding genes to direct their post-transcriptional repression (1). Approximately $50 \%$ of $\mathrm{miR}$ genes are located in cancer-associated genomic regions or in fragile sites, and a number of them have been demonstrated to exhibit tumor suppressor activity, while others have been reported to act as

Correspondence to: Dr Yurong Wen, Center for Translational Medicine, School of Life Science and Technology, Xi'an Jiaotong University, 28 Xianning West Road, Xi'an, Shaanxi 710049, P.R. China

E-mail: yurong.wen@hotmail.com

Key words: microRNA-143, extracellular-signal-regulated kinase 5, cervical cancer, HeLa cells, proliferation, apoptosis oncogenes in various tissues and environments (2). Rescued expression of downregulated or functionally-deficient miRs and/or inhibition of overexpressed miRs may contribute to rebalancing the expression of large gene clusters implicated in cell differentiation, apoptosis, metabolism, immunity, oncogenesis and cancer (3).

Previously, it has been demonstrated that the miR clusters miR-143 and miR-145 at the chromosome 5q32 region are downregulated in various human tumors and are able to suppress tumor growth in cancer of the urogenital $(4,5)$, digestive (6) and respiratory systems (3), as well as in osteosarcoma (7), breast cancer (8) and leukemia (9). Furthermore, numerous types of human cancer cell exhibit a markedly reduced expression of miR-143 and miR-145 compared to normal tissues (10). Accumulating evidence indicates that miR-143 may act as an anti-oncomir in a number of types of cancer (11).

Cervical cancer exhibits an aberrant cellular miR expression pattern (12). miR-143 expression has been reported to be downregulated in human cervical cancer tissues (13). Furthermore, previous studies have revealed that miR-143 is downregulated in HPV-induced pre-neoplastic lesions, which suggests that miR-143 may have a significant role in the early stages of cervical cancer development $(13,14)$. However, the mechanism of miR-143 in apoptosis and cell cycle progression during cervical cancer and the mechanisms underlying these processes remain to be elucidated.

miRs are able to regulate multiple target genes simultaneously (15). miR-143 has been demonstrated to target Kirsten rat sarcoma viral oncogene homolog (KRAS) (16), matrix metalloproteinase-13 (7), epithelial-mesenchymal transition (17), cyclooxygenase-2 (6) and cluster of differentiation $44 \mathrm{v} 3$ (3), and is able to suppress cell growth and metastasis in vitro and in vivo in several types of tumor (13). Among the target genes regulated by miR-143, in silico screening of gene targets for miR-143 was performed using TargetScan (www.targetscan.org). Extracellular-signal-regulated kinase 5 (ERK5), which is an upstream gene of mitogen-activated protein kinase (MAPK), has been reported to be a potential target of miR-143 and to be closely associated with tumorigenesis (18). There is clinical evidence that an increase in ERK5 signaling may be associated with cancer progression. 
For example, miR-143 targeting by ERK5 was demonstrated in prostate cancer (19), bladder cancer (10), gut tumors (20), colon carcinoma (21) and DLD-1 cells (22). This may be due to the fact that ERK5 is able to phosphorylate c-Fos, which is a highly inducible and unstable transcription factor, and has a variety of functions in cell proliferation, differentiation and transformation regulation (23). The activity and stability of c-Fos is affected by several kinases, including ERK1/2, ribosomal s6 kinase, c-Mos, ERK5 and p38, via phosphorylation (23). Therefore, this suggests that targeted therapies against ERK5 may have a more widespread clinical application in numerous types of cancer.

In the present study, the effect of miR-143 overexpression was evaluated in HeLa cervical cancer cells. miR-143 expression in the transfectants was assessed by northern blotting. The results indicated that miR-143 overexpression reduced HeLa cell viability in a dose- and time-dependent manner compared to control cells, via cell counting and 3-(4,5-dimethylthiazol-2-yl)-2,5-diphenyltetrazolium bromide (MTT) assay. The present study also identified that the mechanism of miR-143 inhibition of migration and invasion of HeLa cells may be via targeting ERK5 and its downstream oncoprotein c-Fos.

\section{Materials and methods}

Cell culture, cell viability and morphological study. Human cervical cancer HeLa cells (obtained from the cell bank of the Institutes for Biological Sciences, Shanghai, China) were cultured in RPMI-1640 (Gibco; Thermo Fisher Scientific, Inc., Waltham, MA, USA) containing $10 \%(\mathrm{v} / \mathrm{v})$ heat-inactivated fetal bovine serum (Gibco; Thermo Fisher Scientific, Inc.), $2 \mathrm{mM}$ L-glutamine, $100 \mathrm{U} / \mathrm{ml}$ penicillin and $100 \mu \mathrm{g} / \mathrm{ml}$ streptomycin (Sigma-Aldrich; EMD Millipore, Billerica, MA, USA), under an atmosphere of $95 \%$ air and $5 \% \mathrm{CO}_{2}$ at $37^{\circ} \mathrm{C}$. Cell viability was determined by cell counting and MTT assays. Briefly, the medium in each well was replaced with $250 \mu \mathrm{l}$ of fresh medium containing $0.5 \mathrm{mg} / \mathrm{ml}$ MTT (Sigma-Aldrich; EMD Millipore) and incubated for $4 \mathrm{~h}$ at $37^{\circ} \mathrm{C}$. Following removal of the medium and MTT, the remaining crystals were dissolved in $150 \mu \mathrm{l}$ dimethyl sulfoxide (Sigma-Aldrich; EMD Millipore) and the plate was agitated for 5 min in the dark. The absorbance at $490 \mathrm{~nm}$ was measured using an ELx800 enzyme immunoassay analyzer (BioTek Instruments, Inc. Winooski, VT, USA). In a cell counting assay, $50 \mu \mathrm{l}$ of cells was added to $450 \mu 1$ trypan blue (1:10 dilution) and the calls were counted using a hemocytometer. The results are presented as the mean \pm standard error of quadruplicates of a representative experiment.

Transient transfection. A total of 20 or $40 \mathrm{nM}$ of precursor-miR-143 (Pre-miR-143; 5'-UGAGAUGAAGCA CUGUAGCUC-3') or random sequence negative control (5'-UUCUCCGAACGUGUCACGUTT-3') (Ambion; Thermo Fisher Scientific, Inc.) were transfected into $5 \times 10^{5} \mathrm{HeLa}$ cells using Lipofectamine ${ }^{\circledR} 2000$ transfection reagent (Thermo Fisher Scientific, Inc.), according to the manufacturer's protocol. A second cell transfection was performed at $48 \mathrm{~h}$ after the first transection using the same transfection method for cell viability analyzed by cell counting. To confirm the efficiency of transfection, northern blotting was performed following transient transfection.

Northern blotting. Total RNA for reverse transcription-quantitative polymerase chain reaction (RT-qPCR) analysis was extracted using TRIzol (Invitrogen; Thermo Fisher Scientific, Inc.) as described previously (24) and separated on a $10 \%$ polyacrylamide TBE-urea mini-gel (Invitrogen; Thermo Fisher Scientific. Inc.) for miR analysis, followed by electroblotting onto a Hybond $\mathrm{N}$ nylon filter (GE Healthcare Life Sciences, Chalfont, UK). The membrane was hybridized with an end-labeled oligonucleotide probe (Promega Corporation, Madison, WI, USA) for miR-143 (5'-TGAGCTACAGTGCTT CATCTCA-3') for $2 \mathrm{~h}$ at $42^{\circ} \mathrm{C}$ and washed 3 times with Hank's balanced salt solution buffer. The hybridization was performed in Rapid-Hyb buffer (GE Healthcare Life Sciences). The blot was probed for U6 as a control for equal loading $(25,26)$. Data were analyzed using a Storm 860 PhosphorImager (GE Healthcare Life Sciences). Densitometric analysis was performed by Healthcare ImageQuant TL 7.0 Image Analysis Software (GE Healthcare Life Sciences), as described previously (24).

Target genes. The gene targets for miR-143 were predicted using TargetScan (www.targetscan.org) and the potential target of interest, ERK5, was screened as previously described (19).

$R T$ - $q P C R$. A total of $100 \mathrm{ng}$ RNA was extracted with the miRNeasy kit (Qiagen GmbH, Hilden, Germany) and was further subjected to RT using a reverse transcription kit (New England BioLabs, Inc., Ipswich, MA, USA) according to the manufacturer's protocol. qPCR was performed using a SYBR Green Real-Time PCR Master Mix (Bio-Rad Laboratories, Inc., Hercules, CA, USA) on an iCycler (Bio-Rad Laboratories, Inc.). The PCR reaction consisted of 40 cycles $\left(94^{\circ} \mathrm{C}\right.$ for $45 \mathrm{sec}$, $55^{\circ} \mathrm{C}$ for $30 \mathrm{sec}$ and $72^{\circ} \mathrm{C}$ for $30 \mathrm{sec}$ ) following an initial denaturation step $\left(95^{\circ} \mathrm{C}\right.$ for $\left.20 \mathrm{sec}\right)$. The sequences of the primers used in the present study were as follows: ERK5 forward, 5'-CCTTCGATGTGACCTTTGAC-3' and reverse, 5'-TGA CACCATTGATCTGACCC-3'; $\beta$-actin forward, 5'-ATCGTG CGTGACATTAAGGAGAAG-3' and reverse, 5'-AGGAAG GAAGGCTGGAAGAGTG-3'. Expression of ERK5 relative to $\beta$-actin was determined using the $2^{-\Delta \Delta C q}$ method (27).

Flow cytometric analysis of cell cycle and apoptosis. Cells were harvested by trypsinization, centrifuged at $400 \mathrm{x} g$ for $5 \mathrm{~min}$ at $4^{\circ} \mathrm{C}$, suspended in $0.1 \mathrm{ml}$ of phosphate-buffered saline (PBS) and subsequently fixed by addition of $1.0 \mathrm{ml} 70 \%$ cold ethanol. Following pelleting and removal of ethanol, RNA was extracted using 1 unit of RNase A (Sigma-Aldrich; EMD Millipore). The cells were stained with $50 \mu \mathrm{g} / \mathrm{ml}$ propidium iodide (PI; Sigma-Aldrich; EMD Millipore) for $30 \mathrm{~min}$ at room temperature. The DNA content was subsequently analyzed using cytofluorometry and cell cycle analysis was performed using FACScan software (BD Biosciences, Franklin Lakes, NJ, USA), as described previously (19).

To analyze apoptosis, cells were washed in PBS and centrifuged at $400 \mathrm{x} \mathrm{g}$ for $5 \mathrm{~min}$ at $4^{\circ} \mathrm{C}$. Cells were resuspended in binding buffer (Biolegend, Inc., San Diego, CA, USA), and $5 \mu \mathrm{l}$ of fluorochrome-conjugated Annexin V-fluorescein isothiocyanate (FITC; Roche Diagnostics, Meylan, France) 
and $10 \mu 1$ PI solution were added and incubated with the cells for $10 \mathrm{~min}$ at $4^{\circ} \mathrm{C}$. The percentage of Annexin V-FITC-positive cells was immediately analyzed using a flow cytometer and the data were analyzed using the Modfit LT software for Windows version 3.2 (Verity Software House, Inc., Topsham, ME, USA).

Western blotting. The cells were homogenized in chilled lysis buffer comprising $10 \mathrm{mM}$ Tris- $\mathrm{HCl}$ (pH 7.4), 1\% NP-40, $0.1 \%$ deoxycholic acid, $0.1 \%$ sodium dodecyl sulfate (SDS), $150 \mathrm{mM} \mathrm{NaCl}, 1 \mathrm{mM}$ ethylenediaminetetraacetic acid and $1 \%$ protease inhibitor cocktail (Sigma-Aldrich; EMD Millipore) for $30 \mathrm{~min}$ on ice. Following centrifugation at $16,000 \mathrm{x} \mathrm{g}$ for $20 \mathrm{~min}$ at $4^{\circ} \mathrm{C}$, the supernatants were collected as protein samples. Protein concentrations were assessed with a DC protein assay kit (Bio-Rad Laboratories, Inc.). A total of $10 \mu \mathrm{g}$ of protein lysate was used for western blotting and separated by $10 \%$ SDS-PAGE, followed by electroblotting onto a polyvinylidene difluoride membrane (DuPont, Boston, MA, USA). Following blockage of non-specific binding sites using Tris-Buffered Saline and Tween 20 (TBST) containing 5\% non-fat milk for $1 \mathrm{~h}$, the membrane was incubated with rabbit anti-human ERK5 monoclonal antibody (1:1,000 dilution; clone, D3I5V; catalog no. 12950; Cell Signaling Technology, Inc., Danvers, MA, USA) or mouse anti-human c-Fos monoclonal antibody (1:1,000 dilution; clone, 6-2H-2F; catalog no. sc-447; Santa Cruz Biotechnology, Inc., Dallas, TX, USA) overnight at $4^{\circ} \mathrm{C}$. The membranes were washed three times with TBST and incubated further with horseradish peroxidase-conjugated sheep anti-mouse immunoglobulin (Ig) $\mathrm{G}$, horeradish peroxidase (HRP)-linked whole antibody (catalog no. NA931) or enhanced chemiluminescence donkey anti-rabbit IgG, HRP-linked whole antibody (catalog no. NA934V) (GE Healthcare Life Sciences) for $1 \mathrm{~h}$ at room temperature. The immunoblots were visualized using an enhanced chemiluminescence detection kit (New England BioLabs, Inc.) following washing three times with TBST. Quantification was performed using Imaging $\mathrm{J}$ version 1.45 (National Institutes of Health, Bethesda, MD, USA).

Statistical analysis. Each experiment was performed in triplicate, with the exception of the MTT assay, which was performed in quadruplicate. All statistical analyses were performed using SPSS version 13.0 (SPSS, Inc., Chicago, IL, USA). Data are presented as the mean \pm standard error, and differences between groups were calculated by analysis of variance or $\chi^{2} . \mathrm{P}<0.05$ was considered to indicate a statistically significant difference.

\section{Results}

miR-143 overexpression decreases growth of HeLa cells. It has been demonstrated that transient transfection of human cancer cells with Pre-miR may significantly increase the expression of mature miR (28). The present study initially confirmed the expression of miR-143 following Pre-miR-143 transfection of HeLa cells, and investigated the effect of transient miR-143 overexpression on HeLa cell growth. This was performed by transfecting Pre-miR-143 into HeLa cells, with a random sequence as a negative control. Northern blotting results clearly revealed that miR-143 expression was significantly increased in 20 or $40 \mathrm{nM}$ pre-miR-143 transfected
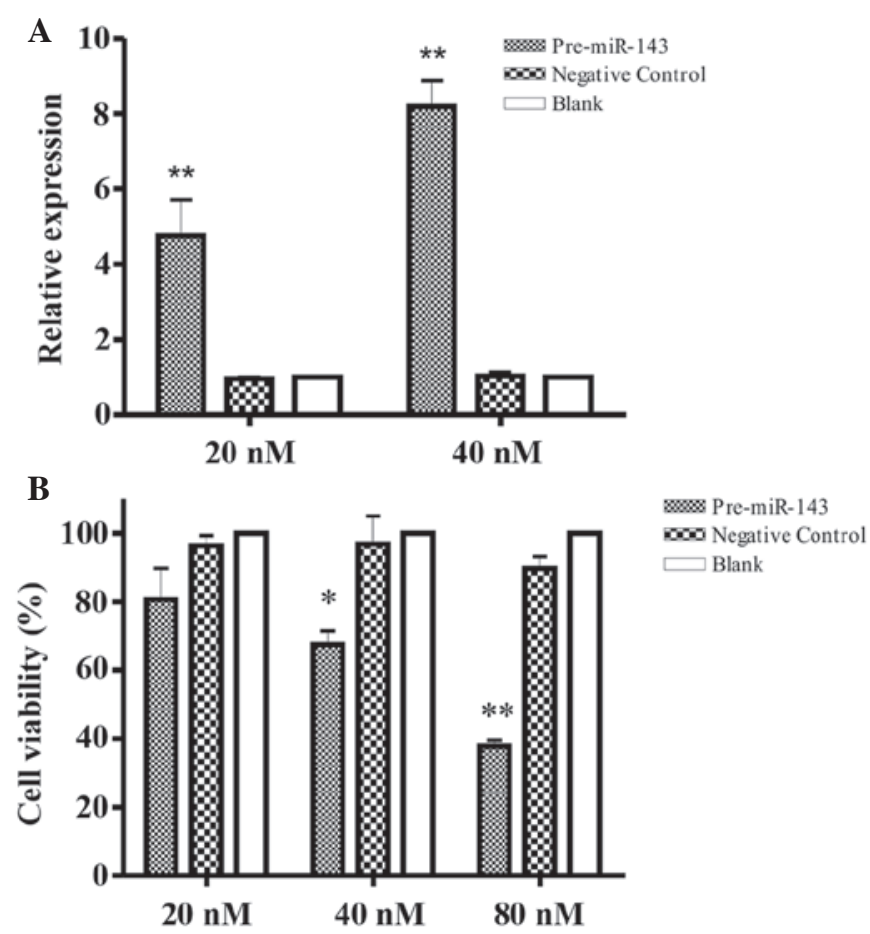

Figure 1. Effect on HeLa cells following transfection with Pre-mir-143. (A) The expression levels of miR-143 in HeLa cells at $36 \mathrm{~h}$ subsequent to the transfection of the cells with Pre-mir-143 or negative control at 20 and $40 \mathrm{nM}$. (B) The relative percentage cell viability analyzed by cell counting was observed in miR-143 transfectants or control transfectants at $72 \mathrm{~h}$. U6 was used as an internal standard. Data are presented as the mean \pm standard error of three independent experiments and each concentration of Pre-mir-143 or negative control transfection was performed in triplicate. ${ }^{*} \mathrm{P}<0.05,{ }^{* *} \mathrm{P}<0.01$ compared with the negative control. miR, microRNA; pre-miR-143, precursor miR-143.

HeLa cells (Fig. 1A), as compared to negative control transfected cells and blank buffer following normalization to U6 expression $(\mathrm{P}<0.05)$.

To evaluate the impact of miR-143 overexpression on the growth of HeLa cells, cell counting and MTT assays were performed on HeLa cells following transient transfection with Pre-miR-143 at 20, 40 and $80 \mathrm{nM}$ respectively. The increased level of Pre-miR-143 (40 and $80 \mathrm{nM}$ ) significantly inhibited HeLa cell growth, compared to negative control transfected HeLa cell and blank buffer groups $(\mathrm{P}=0.091,0.008$ and 0.002 , for 20,40 and $80 \mathrm{nM}$, respectively) as evaluated by cell counting (Fig. 1B). This inhibitory effect on cell growth was not an immediate cell response; rather two consecutive cell transfections at an interval of $48 \mathrm{~h}$ were required. Furthermore, the cell viability was detected at 0, 1, 2, 3 and 4 days using MTT assays. Notably, the results of the present study have shown that 40 and $80 \mathrm{nM}$ Pre-miR-143 transfection significantly suppresses HeLa cell growth in a dose- and time-dependent manner as compared to the negative control transfected HeLa cells (Fig. 2; $\mathrm{P}<0.001$ ).

miR-143 overexpression induces HeLa cell apoptosis. Having validated the impact of miR-143 on the growth rate of transfected HeLa cells, the present study additionally characterized the effect of miR-143 overexpression on biological responses, including the cell cycle and apoptosis, using flow cytometry. The representative cell cycle distribution of 

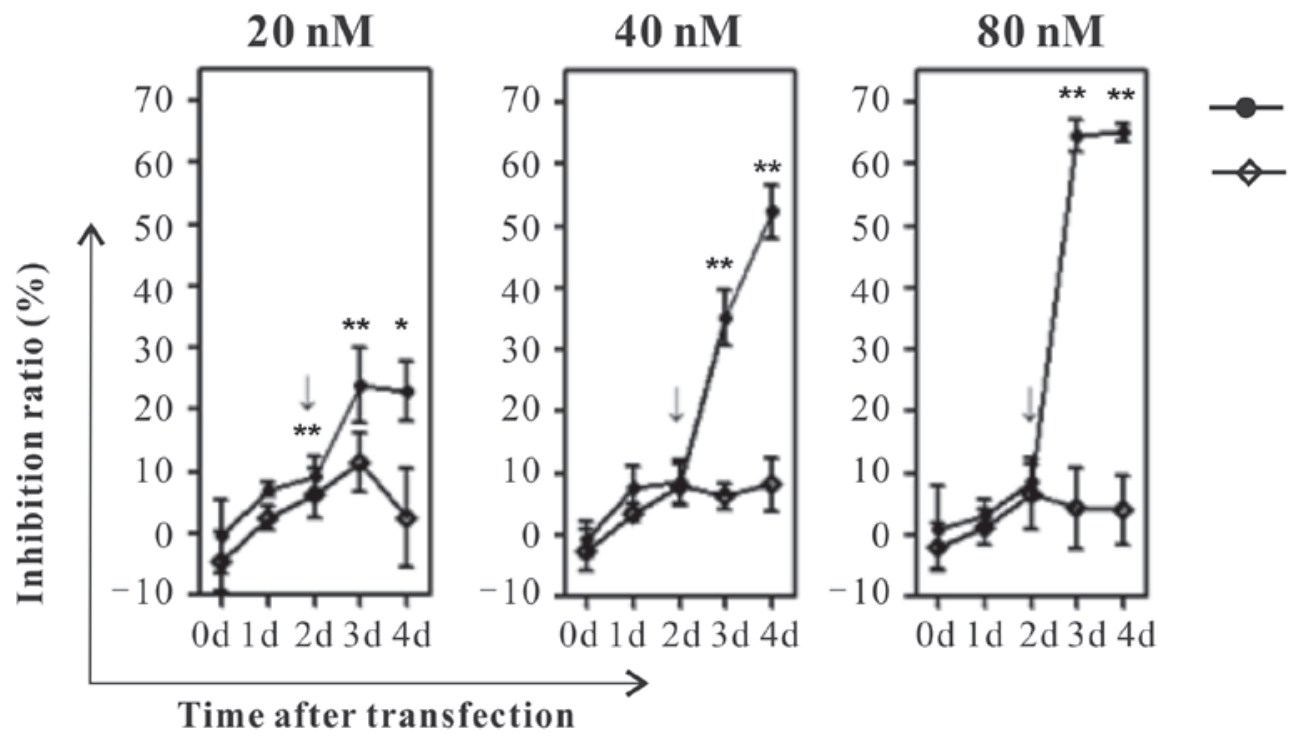

Pre-miR-143

Negative control

Figure 2. Impact of miR-143 overexpression on HeLa cell growth. The $\mathrm{X}$-axis arrow indicates the time points (in days) when the cells received pre-miRNA-143 or negative control (20, 40 and $80 \mathrm{nM}$ ) transfection. Relative cell growth, indicated on the Y-axis, was measured by 3-(4,5-dimethylthiazol-2-yl)-2,5-diphenyltetrazolium bromide assay. Data represent the mean \pm standard error of two independent experiments, with each condition performed in triplicate. " $\mathrm{P}<0.05$, ${ }_{* * *} \mathrm{P}<0.01$ compared with the negative control. miR, microRNA; pre-miR-143, precursor miR-143.

A

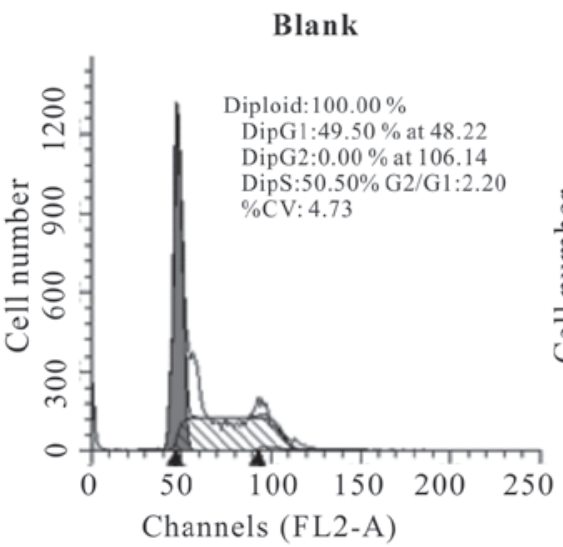

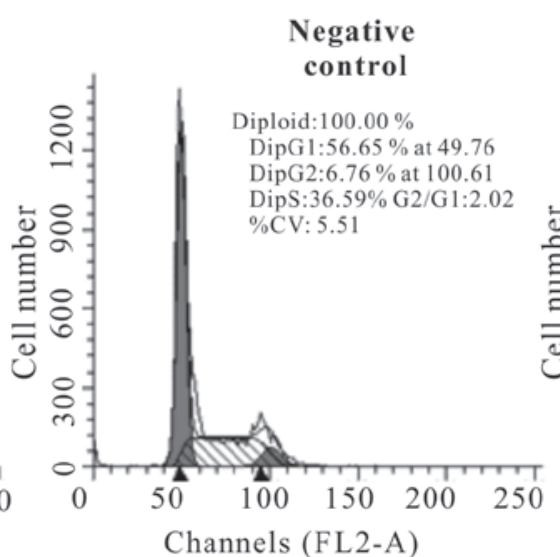

Channels (FL2-A)
Pre-miR-143

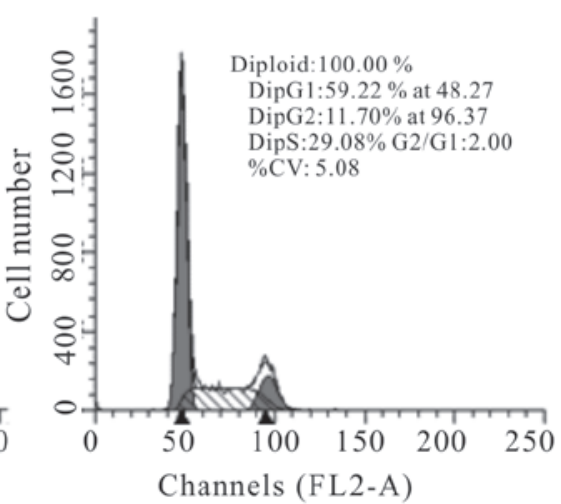

B

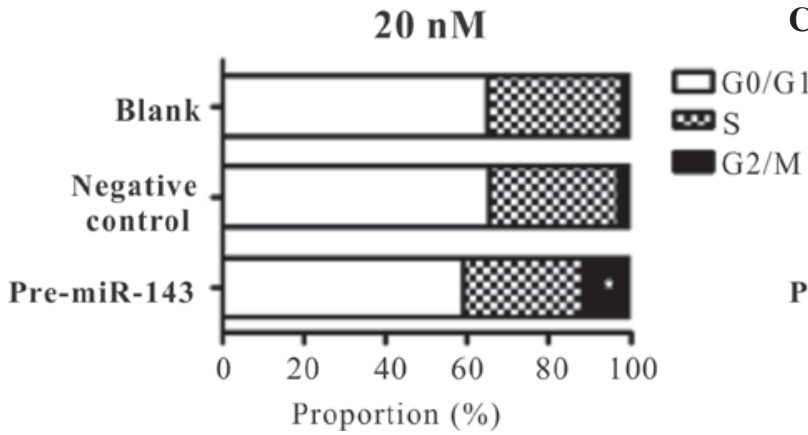

C

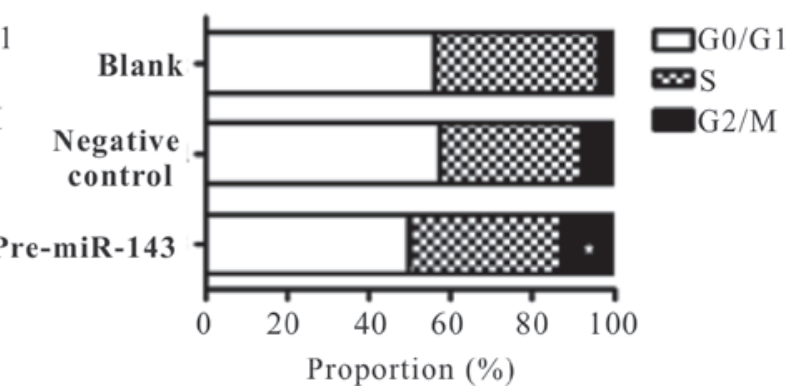

Figure 3. Effect of Pre-miR-143 transfection on the HeLa cell cycle. (A) Fixed cells were treated with RNase and stained with propidium iodide. The representative figures of the blank (left panel), negative control (middle panel) and pre-miR-143 incubated with HeLa cells (right panel) for cell cycle analysis via flow cytometry are presented. The proportion (\%) of G0/G1, S and G2/M phases of the cell cycle are presented for (B) $20 \mathrm{nM}$ or (C) $40 \mathrm{nM}$ concentrations of blank, negative control or Pre-miR-143 incubated with HeLa cells. For each analysis, a minimum of 10,000 cells was counted. miR, microRNA; pre-miR-143, precursor miR-143; CV, coefficient of variance.

confluent is presented for $40 \mathrm{nM}$ Pre-miR-143 transfected and negative control transfected HeLa cells, as well as blank buffer (Fig. 3A). Notably, significant dose-dependent increases in the apoptotic fraction and corresponding decreases in the G0/G1 phase of the cell cycle were observed in the Pre-miR-143 transfected cells. By contrast, cells in $\mathrm{G} 2 / \mathrm{M}$ phase of the cell cycle were increased from 1.78 to $11.65 \%(\mathrm{P}<0.05)$ following $20 \mathrm{nM}$ Pre-miR-143 transfection 
A

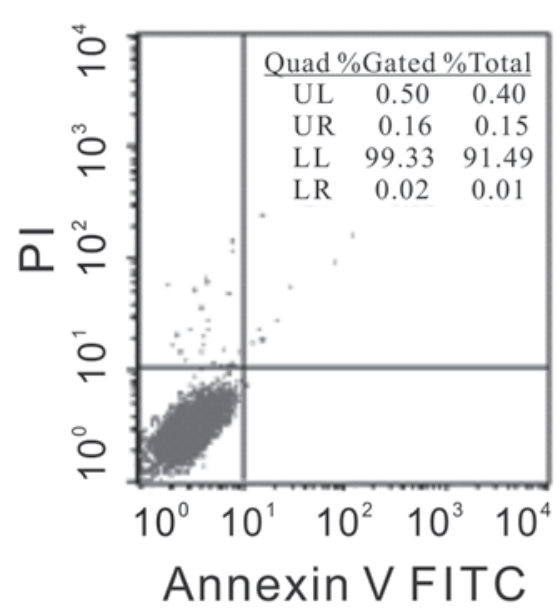

B

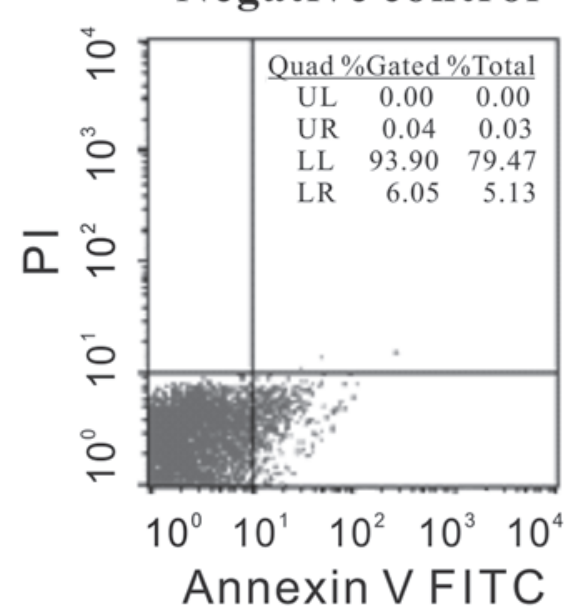

C

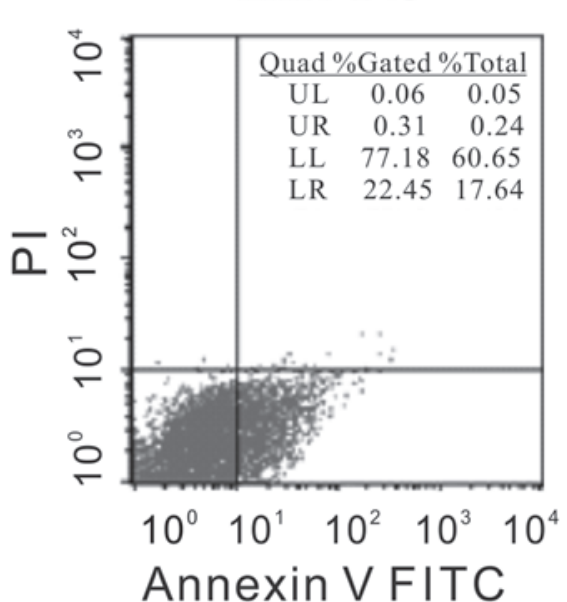

Figure 4. miR-143 induces HeLa cell apoptosis. HeLa cell apoptosis was determined using Annexin V-FITC and PI staining via flow cytometry. Representative graphs from (A) untreated, (B) negative control and (C) Pre-miR-143 transfected HeLa cells are presented. Data (\% of the total population) was reproduced in three replicate experiments. miR, microRNA; FITC, fluorescein isothiocyanate; PI, propidium iodide.

A Blank control Pre-miR-143

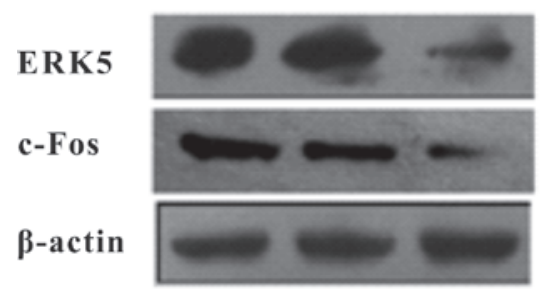

C

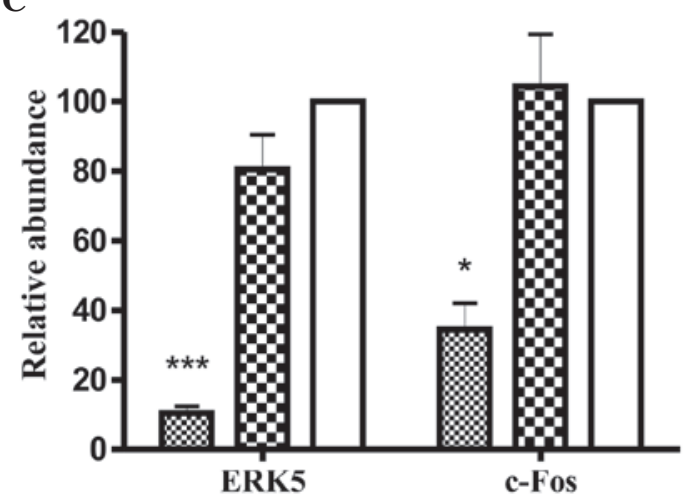

B

ERK5

$\beta$-actin
Blank $\begin{gathered}\text { Negative } \\ \text { control Pre-miR-143 }\end{gathered}$
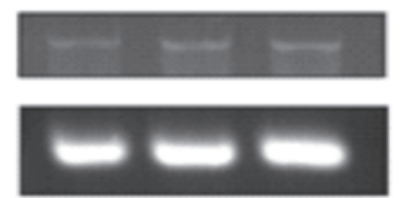

$\$$ Pre-miR-143

and Negative Control

Blank

Figure 5. miR-143 regulates ERK5 expression and the ERK5 downstream oncoprotein c-Fos at the post-transcriptional level. (A) Protein expression levels of ERK5 and c-Fos following miR-143 transfection were analyzed by western blotting. (B) The mRNA level of ERK5 is presented at $36 \mathrm{~h}$ subsequent to the transfection of HeLa cells with precursor miR-143. (C) The quantified western blotting data of ERK5 and c-Fos were statistically analyzed by analysis of variance. Data are presented as the mean \pm standard error of three experiments. ${ }^{*} \mathrm{P}<0.05,{ }^{* * * *} \mathrm{P}<0.001$ compared with the negative control. miR, microRNA; ERK5, extracellular-signal-regulated kinase 5.

and 3.5 to $12.99 \%$ following $40 \mathrm{nM}$ Pre-miR-143 transfection $(\mathrm{P}<0.001$; Fig. 3B and $\mathrm{C})$.

To additionally validate these results, the impact of miR-143 overexpression on the apoptosis of HeLa cells was evaluated by PI and Annexin V-FITC staining via flow cytometry. As shown by representative figures, the Annexin V-FITC staining signal of $40 \mathrm{nM}$ Pre-miR-143 transfected cells showed a right shift in the $\mathrm{X}$-axis compared with the negative control transfected HeLa cells and the blank cells. The apoptotic rate $(37.51 \pm 0.032 \%)$ of miR-143 overexpressed HeLa cells was significantly increased compared to the apoptotic rate of negative control transfected cells $(20.27 \pm 0.045 \%$; $\mathrm{P}<0.05$; Fig. 4).

miR-143 downregulates the expression of ERK5 and c-Fos. In silico prediction of gene targets for miR-143 was performed using TargetScan (www.targetscan.org) and ERK5 was screened as a potential target. ERK5, also known as big MAPK, is activated by oxidative stress, hyperosmolarity and certain growth factors (29). Unlike other MAPK members, ERK5 has a unique large C-terminal region, whose function 
has not been fully elucidated (30). It has been shown that ERK5 directly interacts with, phosphorylates and activates a number of transcription factors, including c-Myc, Sapla, c-Fos, Fos-related antigen 1 and myocyte enhancer factor-2 family members (29). ERK5 is important for promoting cell proliferation, differentiation and neuronal survival (30). Its activity has been previously considered to be dependent on its phosphorylation by MEK5; however, post-transcriptional regulation in this process is also considered to play a role, as has been previously reported (19). Overexpression of miR-143 has been demonstrated to downregulate ERK5 expression in human bladder cancer cells (10), HCT116 human colon carcinoma cells (21) and LNCaP prostate cancer cell lines (19). To experimentally validate regulation of miR-143 on its potential target ERK5, the present study analyzed ERK5 expression in HeLa cells following transient transfection with Pre-miR-143. Notably, ERK5 expression was inversely correlated with miR-143 expression in HeLa cells as demonstrated by western blot analysis. In a representative image shown as Fig. 5A, the ERK5 protein level in the HeLa cells transfected with Pre-miR-143 was decreased. Whereas the mRNA level of ERK5 was almost unaffected, as confirmed by RT-qPCR (Fig. 5B), when compared with the negative control and blank cells, the ERK5 protein expression in Pre-miR-143 transfectant was significantly downregulated $(\mathrm{P}<0.001$; Fig.5C). Furthermore, activated ERK5 modulates cell differentiation and proliferation via c-Fos, c-Myc, cyclin D1 and nuclear factor-кB activation. Additionally, с-Fos has been demonstrated to have a regulatory effect via a signaling pathway involving ERK5 $(23,26)$. Therefore, the transcription level and the expression level of c-Fos were also evaluated. Notably, the c-Fox protein expression was reduced concurrently with the downregulation of ERK5 ( $\mathrm{P}<0.05$; Fig. 5C). This indicates that ERK5 may be negatively regulated by miR-143 at the post-transcriptional level, which additionally decreases downstream c-Fos oncoprotein expression.

\section{Discussion}

miR-143 is one of the most prominent miRs implicated in the genesis and progression of human cancer. It has been implicated in the promotion of tumor growth, proliferation, apoptosis resistance and resistance to gemcitabine-based chemotherapy (31). Furthermore, a number of studies have identified that miR-143 was downregulated in various tumor types (32-35). The expression levels of miR-143 and -145 were observed to be decreased in the majority of human gastric cancer cases, and growth inhibition and increased sensitivity to 5-fluorouracil was reported following transfection with miR-143 (36). It has also been reported that miR-143 expression is significantly downregulated in bladder tumor tissues compared with normal adjacent tissues, and miR-143 transfection into EJ and T24 cells significantly inhibited cell proliferation (37). Taken together, the results of a number of studies, including the present, support the hypothesis that miR-143 may be one of the most relevant tumor suppressors among the class of miRs.

However, limited efforts have been made to elucidate the role of miR-143 in cervical cancer. The molecular mechanism modulated by miR-143, leading to cell growth inhibition and death remains to be fully elucidated and the role of miR-143 in regulation of the cell cycle and apoptosis is unclear. Lin et al (38) used a direct sequencing method to characterize the profiles of miRs and other small RNA segments for six human cervical carcinoma cell lines and five normal cervical samples, confirmed with a panel of 29 matched pairs of human cervical cancer and normal cervical samples. Reduced expression of miR-143 and increased expression of miR-21 were observed in cervical cancer samples, suggesting the potential value of these miRs as tumor markers $(24,38)$.

The present study demonstrates that miR-143 is a negative regulator of HeLa cell growth. It may additionally be speculated that miR-143 can induce apoptosis, at least in part, via negatively regulating ERK5. As in the present transfection experiments ERK5 mRNA level was unaltered, contrasting to the significant change in ERK5 protein levels, it may be proposed that the main mechanism of miR-143-induced ERK5 suppression occurs at a post-transcriptional level.

To the best of our knowledge, the results of the present study comprise the first report of a causal association between miR-143 and G2-M progression. Zen et al (39) reported that downregulation of MAPK7 by small interfering RNA suppressed the growth of SNU449 cells, which comprise the HCC cell line with the greatest amplification and overexpression of MAPK7. ERK5, which is phosphorylated during the G2/M phases of the cell cycle, may regulate entry into mitosis in SNU449 cells (40). As a significant step in determining its role in cervical tumorigenesis, the present study identifies a novel function for miR-143/ERK5 in the regulation of G2-M transition.

ERK5 has been demonstrated to inhibit cancer cell viability, achieved in part by inhibiting the nuclear export of c-Fos and disrupting the interaction of c-Fos with ubiquitin protein ligase E3 component $\mathrm{N}$-recognin 1 by phosphorylating Ser32 (23). Additional mechanisms and targets of miR-143 besides ERK5 are likely to contribute to miR-143-induced tumor cell growth inhibition. It has been reported that miR-143 is significant in suppressing colorectal cancer cell growth via inhibition of KRAS translation (41). Additionally, restoration of miR-143 expression in colon cell lines decreased tumor cell growth and soft-agar colony formation, and downregulated DNA (cytosine-5)-methyltransferase 3A (DNMT3A) expression in terms of mRNA and protein levels. DNMT3A has been demonstrated to be a direct target of miR-143 by luciferase reporter assay (42).

An improved understanding of the signaling pathway investigated in the present study will bring us closer to understanding the molecular mechanisms underlying cervical cancer and may lead to the development of novel approaches for detection and therapy. Taken together with the results of previous correlational studies on miR-143 and ERK5, the results of the present study indicate that strategies rescuing miR-143 expression, enhancing the miR-143/ERK5 interaction, or inhibiting ERK5 expression may have a strong rationale for therapeutic applications in the treatment of cancer.

\section{Acknowledgements}

The present study was financially supported by the Fundamental Research Funds for the Central Universities (grant no. XJJ2015056) and (grant no. 1191320048). 


\section{References}

1. Bartel DP: MicroRNAs: Target recognition and regulatory functions. Cell 136: 215-233, 2009.

2. Ha M and Kim VN: Regulation of microRNA biogenesis. Nat Rev Mol Cell Biol 15: 509-524, 2014.

3. Ma QP, Jiang Q, Pu Q, Zhang X, Yang W, Wang Y, Ye S, Wu S, Zhong G, Ren J, et al: MicroRNA-143 inhibits migration and invasion of human non-small-cell lung cancer and its relative mechanism. Int J Biol Sci 9: 680-692, 2013.

4. Song T, Zhang X, Wang C, Wu Y, Dong J, Gao J, Cai W and Hong B: Expression of miR-143 reduces growth and migration of human bladder carcinoma cells by targeting cyclooxygenase-2. Asian Pac J Cancer Prev 12: 929-933, 2011

5. Xu B, Niu X, Zhang X, Tao J, Wu D, Wang Z, Li P, Zhang W, Wu H, Feng N, et al: mir-143 decreases prostate cancer cells proliferation and migration and enhances their sensitivity to docetaxel through suppression of KRAS. Mol Cell Biochem 350: 207-213, 2011.

6. Wu XL, Cheng B, Li PY, Huang HJ, Zhao Q, Dan ZL, Tian DA and Zhang P: MicroRNA-143 suppresses gastric cancer cell growth and induces apoptosis by targeting COX-2. World J Gastroenterol 19: 7758-7765, 2013.

7. Osaki M, Takeshita F, Sugimoto Y, Kosaka N, Yamamoto Y, Yoshioka Y, Kobayashi E, Yamada T, Kawai A, Inoue T, et al: MicroRNA-143 regulates human osteosarcoma metastasis by regulating matrix metalloprotease-13 expression. Mol Ther 19 1123-1130, 2011.

8. Chang YY, Kuo WH, Hung JH, Lee CY, Lee YH, Chang YC, Lin WC, Shen CY, Huang CS, Hsieh FJ, et al: Deregulated microRNAs in triple-negative breast cancer revealed by deep sequencing. Mol Cancer 14: 36, 2015.

9. Akao Y, Nakagawa Y, Kitade Y, Kinoshita T and Naoe T: Downregulation of microRNAs-143 and -145 in B-cell malignancies. Cancer Sci 98: 1914-1920, 2007.

10. Noguchi S, Yasui Y, Iwasaki J, Kumazaki M, Yamada N, Naito S and Akao Y: Replacement treatment with microRNA-143 and -145 induces synergistic inhibition of the growth of human bladder cancer cells by regulating PI3K/Akt and MAPK signaling pathways. Cancer Lett 328: 353-361, 2013.

11. Ahmad I, Singh LB, Yang ZH, Kalna G, Fleming J, Fisher G, Cooper C, Cuzick J, Berney DM, Møller H, et al: Mir143 expression inversely correlates with nuclear ERK5 immunoreactivity in clinical prostate cancer. Br J Cancer 108: 149-154, 2013

12. Hou LJ and Zhai JJ: Aberrant expression profile of translationally controlled tumor protein and tumor-suppressive microRNAs in cervical cancer. J BUON 20: 1504-1509, 2015.

13. Honegger A, Schilling D, Bastian S, Sponagel J, Kuryshev V, Sültmann H, Scheffner M, Hoppe-Seyler K and Hoppe-Seyler F: Dependence of intracellular and exosomal microRNAs on viral E6/E7 oncogene expression in HPV-positive tumor cells. PLoS Pathog 11: e1004712, 2015.

14. Wang XH, Tang S, Le SY, Lu R, Rader JS, Meyers C and Zheng ZM: Aberrant expression of oncogenic and tumor-suppressive microRNAs in cervical cancer is required for cancer cell growth. PLoS One 3: e2557, 2008.

15. Pinweha P, Rattanapornsompong K, Charoensawan V and Jitrapakdee S: MicroRNAs and oncogenic transcriptional regulatory networks controlling metabolic reprogramming in cancers. Comput Struct Biotechnol J 14: 223-233, 2016.

16. Mekenkamp LJ, Tol J, Dijkstra JR, de Krijger I, Vink-Börger ME, van Vliet S, Teerenstra S, Kamping E, VerwielE, Koopman M, et al: Beyond KRAS mutation status: Influence of KRAS copy number status and microRNAs on clinical outcome to cetuximab in metastatic colorectal cancer patients. BMC Cancer 12: 292, 2012

17. Peng X, Guo W, Liu T, Wang X, Tu X, Xiong D, Chen S, Lai Y, Du H, Chen G, et al: Identification of miRs-143 and-145 that is associated with bone metastasis of prostate cancer and involved in the regulation of EMT. PLoS One 6: e20341, 2011.

18. Lochhead PA, Gilley R and Cook SJ: ERK5 and its role in tumour development. Biochem Soc Trans 40: 251-256, 2012.

19. Clapé C, Fritz V, Henriquet C, Apparailly F, Fernandez PL, Iborra F, Avancès C, Villalba M, Culine S and Fajas L: miR-143 interferes with ERK5 signaling, and abrogates prostate cancer progression in mice. PLoS One 4: e7542, 2009.

20. Takaoka Y, Shimizu Y, Hasegawa H, Ouchi Y, Qiao S, Nagahara M, Ichihara M, Lee JD, Adachi K, Hamaguchi M and Iwamoto T: Forced expression of miR-143 represses ERK5/c-Myc and p68/p72 signaling in concert with miR-145 in gut tumors of Apc(Min) mice. PLoS One 7: e42137, 2012.
21. Borralho PM, Simões AE, Gomes SE, Lima RT, Carvalho T, Ferreira DM, Vasconcelos MH, Castro RE and Rodrigues CM: miR-143 overexpression impairs growth of human colon carcinoma xenografts in mice with induction of apoptosis and inhibition of proliferation. PLoS One 6: e23787, 2011.

22. Nakagawa Y, Iinuma M, Naoe T, Nozawa Y and Akao Y: Characterized mechanism of alpha-mangostin-induced cell death: Caspase-independent apoptosis with release of endonuclease-G from mitochondria and increased miR-143 expression in human colorectal cancer DLD-1 cells. Bioorg Med Chem 15: 5620-5628, 2007.

23. Sasaki T, Kojima H, Kishimoto R, Ikeda A, Kunimoto H and Nakajima K: Spatiotemporal regulation of c-Fos by ERK 5 and the E3 ubiquitin ligase UBR1, and its biological role. Mol Cell 24: 63-75, 2006

24. Kajimoto K, Naraba H and Iwai N: MicroRNA and 3T3-L1 pre-adipocyte differentiation. RNA 12: 1626-1632, 2006.

25. Corney DC, Flesken-Nikitin A, Godwin AK, Wang W and Nikitin AY: MicroRNA-34b and MicroRNA-34c are targets of p53 and cooperate in control of cell proliferation and adhesion-independent growth. Cancer Res 67: 8433-8438, 2007.

26. Peltier HJ and Latham GJ: Normalization of microRNA expression levels in quantitative RT-PCR assays: Identification of suitable reference RNA targets in normal and cancerous human solid tissues. RNA 14: 844-852, 2008

27. Livak and Schmittgen: Analysis of relative gene expression data using real-time quantitative PCR and the $2-\Delta \Delta \mathrm{Ct}$ method. Methods 25: 402-408, 2001.

28. Liu L, Yu X, Guo X, Tian Z, Su M, Long Y, Huang C, Zhou F, Liu M, Wu X and Wang X: miR-143 is downregulated in cervical cancer and promotes apoptosis and inhibits tumor formation by targeting Bcl-2. Mol Med Rep 5: 753-760, 2012.

29. Simões AE, Rodrigues CM and Borralho PM: The MEK5/ERK5 signalling pathway in cancer: A promising novel therapeutic target. Drug Discov Today: S1359-S6446(16)30228-8, 2016.

30. Nithianandarajah-Jones GN, Wilm B, Goldring CE, Müller J and Cross MJ. ERK5: Structure, regulation and function. Cell Signal 24: 2187-2196, 2012

31. Chen B, Li H, Zeng X, Yang P, Liu X, Zhao X and Liang S: Roles of microRNA on cancer cell metabolism. J Transl Med 10: 228, 2012.

32. Truta A, Popon TA, Saraci G, Ghervan L and Pop IV: Novel non invasive diagnostic strategies in bladder cancer. Clujul Med 89: 187-192, 2016.

33. Goto Y, Kurozumi A, Enokida H, Ichikawa T and Seki N. Functional significance of aberrantly expressed microRNAs in prostate cancer. Int J Urol 22: 242-252, 2015.

34. Banno K, Iida M, Yanokura M, Kisu I, Iwata T, Tominaga E, Tanaka K and Aoki D: MicroRNA in cervical cancer: OncomiRs and tumor suppressor miRs in diagnosis and treatment. ScientificWorldJournal 2014: 178075, 2014

35. Pan Y, Meng M, Zhang G, Han H and Zhou Q: Oncogenic microRNAs in the genesis of leukemia and lymphoma. Curr Pharm Des 20: 5260-5267, 2014

36. Bai L, Mao R, Wang J, Ding L, Jiang S, Gao C, Kang H, Chen X, Sun $\mathrm{X}$ and Xu J: ERK1/2 promoted proliferation and inhibited apoptosis of human cervical cancer cells and regulated the expression of c-Fos and c-Jun proteins. Med Oncol 32: 57, 2015.

37. Ng EK, Tsang WP, Ng SS, Jin HC, Yu J, Li JJ, Röcken C, Ebert MP, Kwok TT and Sung JJ: MicroRNA-143 targets DNA methyltransferases 3A in colorectal cancer. Br J Cancer 101: 699-706, 2009.

38. Lin T, Dong W, Huang J, Pan Q, Fan X, Zhang C and Huang L: MicroRNA-143 as a tumor suppressor for bladder cancer. J Urol 181: 1372-1380, 2009.

39. Zen K, Yasui K, Nakajima T, Zen Y, Zen K, Gen Y, Mitsuyoshi H, Minami M, Mitsufuji S, Tanaka S, et al: ERK5 is a target for gene amplification at $17 \mathrm{pl} 1$ and promotes cell growth in hepatocellular carcinoma by regulating mitotic entry. Genes Chromosomes Cancer 48: 109-120, 2009.

40. Lui WO, Pourmand N, Patterson BK and Fire A: Patterns of known and novel small RNAs in human cervical cancer. Cancer Res 67: 6031-6043, 2007.

41. Deftereos G, Corrie SR, Feng QH, Morihara J, Stern J, Hawes SE and Kiviat NB: Expression of mir-21 and mir-143 in cervical specimens ranging from histologically normal through to invasive cervical cancer. PLoS One 6: e28423, 2011.

42. Cude K, Wang YP, Choi HJ, Hsuan SL, Zhang H, Wang CY and Xia Z: Regulation of the G2-M cell cycle progression by the ERK5-NFkappa B signaling pathway. J Cell Biol 177: 253-264, 2007. 